ORIGINAL ARTICLE

\title{
Empowerment of Anganwadi Workers in Oral Health Care: A Kerala Experience
}

\author{
Sunu Alice Cherian ${ }^{1}$, Elizabeth Joseph ${ }^{2}$, Rupesh $S^{3}$, Gibi Syriac ${ }^{4}$, John Philip ${ }^{5}$
}

\begin{abstract}
Introduction: Oral diseases are a serious public health problem, which affects the overall health of a person. The lack of available and affordable oral health services, especially in a developing country like India, not only results in aggravation of the disease, but also enhances the cost of treatment and care. Education and involvement of community workers like Anganwadi workers aid to remove stigma, discrimination and provide better atmosphere conducive for patients with various diseases.

Aim: To assess the knowledge and practice of oral health care among the AWWs of the Pulikeezh block Panchayath before and after an oral health education training.

Materials and methods: A self-administered questionnaire was distributed to anganwadi workers of the Pulikeezh block Panchayath, Thiruvalla, Kerala before and after an oral health education training within a period of 3 months.

Result: The mean knowledge and practice scores in the pretest were found to be $9.6+2.2$ and $5.0+1.0$ respectively. The posttest conducted after a 3-month period showed an increase in the knowledge and practice score with a mean of $10.9+2.2$ and $5.7+0.6$ respectively. The increase in knowledge and practice was statistically significant $(p<0.0001)$.

Conclusion: Empowered women are recognizably key agents in the change process who can play an effective role for health promotion. AWWs can function as oral health guides who can create awareness and help in prevention oral diseases.

Clinical significance: As the oral health of an individual is set in the preschool period and more than $90 \%$ of dental diseases are preventable; preventive factors established around this age will determine the person's dental health for many years to come. The inclusion of oral health education in Anganwadi centers can be helpful in prevention of dental diseases.
\end{abstract}

Keywords: Anganwadi workers, Knowledge, Oral health education, Practice, Preexperimental study.

International Journal of Clinical Pediatric Dentistry (2019): 10.5005/jp-journals-10005-1636

\section{INTRODUCTION}

Oral diseases are a serious public health problem, which affect the overall health of a person. ${ }^{1}$ The lack of available and affordable oral health services especially in a developing country like India, not only results in aggravation of the disease, but also enhances the cost of treatment and care.

Oral health literacy, like general health literacy, incorporates the capacity of a person to learn and use information about oral health in making decisions about their oral health. Poor oral health literacy can bring about significant challenges. ${ }^{2}$ The sharing of risk factors between oral and general health, and the effects on the later development of diseases point to practical and economic reasons for integrating oral health promotion efforts. This can achieve multiple aims if started in the early childhood itself. Such interventions provide improved oral health knowledge, behaviors, and self-efficacy of parents/caregivers in the short-term.

The anganwadi (AW) - meaning courtyard, is a childcare center located within the village or the slum area itself. It is the center point for the delivery of services at community levels to children below six years of age, adolescent girls pregnant women, and nursing mothers. The AW is a meeting ground where groups of women/mothers can come together, with other frontline workers, to promote awareness and joint action for child development and women's empowerment. All services of the Integrated Child Development Services (ICDS) are provided through the AW in an integrated manner to enhance their impact on childcare. Each AW is run by an anganwadi worker (AWW) supported by a helper in integrated service delivery, and improved linkages with the health system-thus increasing the capacity of community and women,
1-3,5 Department of Pedodontics, Pushpagiri College of Dental Sciences, Thiruvalla, Kerala, India

${ }^{4}$ Department of Pedodontics, Government Dental College, Kottayam, Kerala, India

Corresponding Author: Sunu Alice Cherian, Department of Pedodontics, Pushpagiri College of Dental Sciences, Thiruvalla, Kerala, India, Phone: +91 9495682748, e-mail: djohn30@rediffmail.com

How to cite this article: Cherian SA, Joseph E, et al. Empowerment of Anganwadi Workers in Oral Health Care: A Kerala Experience. Int J Clin Pediatr Dent 2019;12(4):268-272.

Source of support: Nil

Conflict of interest: None

especially mothers for childcare, development and survival. They provide services like, pre-school formal education, nutrition and health education supplementary nutrition, referral services, auxillary nurse midwife (ANM) in immunization, health check-ups. ${ }^{3}$ AWWs are trained regularly on behavior change communication (BCC) and capacity building strategies along with health education. ${ }^{4}$

The concept of health education is changing and is directed towards a common risk factor approach. ${ }^{5}$ Education and involvement of community workers, aid to remove stigma, discrimination and provide better atmosphere conducive for patients with various diseases, even HIV. ${ }^{6}$ Hence, health education not only plays to improve physical health, but also removes the myths and broadens the mindset of the society. Oral health education (OHED) is a widely used effective intervention at school settings that has resulted in induced changes in oral habits, knowledge, practice and routine. ${ }^{7-9}$ 
As the oral health of an individual is set in the pre-school period and more than $90 \%$ of dental diseases are preventable; preventive factors established around this age will determine the person's dental health for many years to come. ${ }^{10}$ The inclusion of oral health education in anganwadi centers has been greatly advised..$^{11,12}$

In general, the AWWs have been scarcely involved in oral health education and they have been reported to have a low to medium knowledge and practice regarding oral health. ${ }^{13-16}$ Hence, the study conducted to assess the knowledge and practice of oral health care among the AWWs of the Pulikeezh Block Panchayat, provides an oral health education training and assesses its impact on their knowledge and practice.

\section{Materials and Methods}

The study was conducted among the Anganwadi workers of the Pulikeezh Block Panchayat, which is situated in Tiruvalla Taluk in the district of Pathanamthitta, Kerala, India. The Pulikeezh Block Panchayat was formed in $1995 .{ }^{17}$ This block includes five panchayats (local self-governing bodies) of Kadapra, Kuttoor, Nedumpuram, Niranam, and Peringara and one municipality (Tiruvalla). There are 155 anganwadi centers in this block panchayat which is served by an AWW and a helper each. It caters to the needs of about 1,500 children.

A self-administered questionnaire was developed in English, which was translated to Malayalam and then back translated to English to avoid any linguistic errors. Content validation of the questionnaire was done by five subject experts and it was modified based on their comments. A pilot study was done on another group of AWWs from a different location before the actual study for validation.

The questionnaire was divided into 3 parts. Part 1 contained baseline variables, such as age, number of children in the anganwadi center, years of experience, education, and location. In part 2, questions regarding knowledge on oral health care were included and part 3 dealt with questions on practice.

Ethical clearance was obtained from the ethics committee of the institution and written consent was obtained from each AWW after explaining the purpose of the study.

The questionnaire survey and oral health educational training were done on the day of their monthly meeting. The questionnaire survey was conducted and announced to avoid bias. The forms were distributed and collected back from the AWWs $(n=145)$ on the same day. This constituted the baseline pre-intervention data and the filled up forms were collected for baseline data on the same day for the pre-intervention data.

The oral health educational training program was given with the aid of power point presentation. Various topics related to diet and oral care during pregnancy, infant oral care, teething, importance of regular dental visits, feeding habits, healthy dietary habits, oral habits and dental caries process were explained. Method of correct tooth brushing was also demonstrated with live model. This was followed by an interactive discussion where their doubts regarding pediatric oral health were cleared. After three months, the same questionnaire was distributed unannounced on the day of their meeting and collected back on the same day. This constituted the post-intervention data.

The data were entered and analyzed statistically. Since there was a difference in the number of study participants in pretest ( $n=145)$ and posttest $(n=138)$, respondents who attended both pretest and posttest $(n=131)$ were selected for the prepost analysis.
The gain in knowledge and practice scores were calculated as the difference between the post and pre-intervention scores. KruskalWallis test was used to determine the relationship between baseline data and gain in knowledge and practice scores. Wilcoxon signed rank test was used for comparing the pre-study and post-study knowledge and practice scores.

\section{Results}

The oral health educational training had a significant impact on the increase in knowledge and practice of the Anganwadi workers of the Pulikeezh Block Panchayat. Table 1 gives the baseline characteristics of the 131 AWWs.

\section{Pretest}

The AWWs had moderate knowledge and practice in oral health hygiene in the pretest. The mean knowledge and practice scores in the pretest were found to be $9.6 \pm 2.2$ and $5.0 \pm 1.0$, respectively. More than $50 \%$ of the AWWs responded wrongly to certain knowledge questions like problems with baby teeth can affect adult teeth (Q2), it is necessary to do fillings in baby's teeth (Q3), frequent and prolonged breast/bottle feeding can cause tooth decay (Q7), nighttime bottle/breast feeding can cause tooth decay (Q11) and to the question relating to the practice of giving sweets to the children often $(\mathrm{Q} 2)$.

\section{Posttest}

The posttest conducted after a 3 month period showed an increase in the knowledge and practice score with a mean of $10.9 \pm 2.2$ and $5.7 \pm 0.6$, respectively. The increase was statistically significant $(p<0.0001)$.

Table 1: Baseline characteristics of the AWW

\begin{tabular}{|c|c|c|}
\hline Characteristics & No. & $\%$ \\
\hline \multicolumn{3}{|l|}{ Age in years } \\
\hline$<40$ & 22 & 16.8 \\
\hline $40-54$ & 85 & 64.9 \\
\hline$\geq 55$ & 24 & 18.3 \\
\hline \multicolumn{3}{|l|}{ Years of experience } \\
\hline$<5$ & 26 & 19.8 \\
\hline $6-16$ & 43 & 32.8 \\
\hline $17-27$ & 19 & 14.5 \\
\hline$\geq 28$ & 43 & 32.8 \\
\hline \multicolumn{3}{|l|}{ Education } \\
\hline Matriculate & 78 & 59.5 \\
\hline High school & 48 & 36.6 \\
\hline Degree & 5 & 3.8 \\
\hline \multicolumn{3}{|l|}{ Area } \\
\hline Kadapra & 21 & 16.0 \\
\hline Kuttoor & 17 & 13.0 \\
\hline Nedumpuram & 10 & 7.6 \\
\hline Niranam & 14 & 10.7 \\
\hline Peringara & 22 & 16.8 \\
\hline Tiruvalla Muncipality & 47 & 35.9 \\
\hline \multicolumn{3}{|c|}{ No. of children in Anganwadi schools } \\
\hline Mean \pm SD & \multicolumn{2}{|c|}{$11.7 \pm 4.2$} \\
\hline Range & \multicolumn{2}{|c|}{$1-25$} \\
\hline
\end{tabular}

$n=131$ 
Table 2: Pre- and post-scores on knowledge and practice of oral health

\begin{tabular}{lllllll}
\hline & \multicolumn{3}{c}{ Pre-score } & & \multicolumn{2}{c}{ Post-score } \\
\cline { 2 - 3 } Score on & Mean $\pm S D$ & Median & & Mean $\pm S D$ & Median & p value \\
\hline Knowledge & $9.6 \pm 2.2$ & 10.00 & & $10.9 \pm 2.2$ & 11.00 & 0.0001 \\
Practice & $5.0 \pm 1.0$ & 5.00 & & $5.7 \pm 0.6$ & 6.00 & 0.0001 \\
\hline$n=131$ & & & & & &
\end{tabular}

Table 3: Percent of correct answers for knowledge questions in pre- and posttest

\begin{tabular}{|c|c|c|c|c|c|}
\hline S. no. & Questions & Pretest & Posttest & pvalue & P diff \\
\hline Q1 & When does the first baby tooth appear in the child's mouth? & 58.8 & 72.5 & 0.018 & $1.3 \pm 2.5(-7$ to -8$)$ \\
\hline Q2 & Problems with baby teeth can affect adult teeth & 35.1 & 47.3 & 0.018 & \\
\hline Q3 & It is necessary to do fillings in baby's teeth & 26.7 & 37.4 & 0.027 & \\
\hline Q4 & Mother's diet during pregnancy will affect baby's teeth & 80.9 & 84.0 & 0.465 & \\
\hline Q5 & Sugar is an etiological factor for tooth decay & 86.3 & 93.1 & 0.061 & \\
\hline Q6 & Fluoride in toothpaste is important for preventing caries in teeth & 90.2 & 84.7 & 0.002 & \\
\hline Q7 & Frequent and prolonged breast/bottle feeding can cause tooth decay & 42.7 & 70.2 & 0.0001 & \\
\hline Q8 & Bottle feeding after the eruption of primary teeth can cause tooth decay & 78.6 & 75.6 & 0.546 & \\
\hline Q9 & $\begin{array}{l}\text { Children need elder's help and supervision with cleaning teeth until they } \\
\text { are } 8 \text { years of age }\end{array}$ & 96.9 & 98.5 & 0.999 & \\
\hline Q10 & Balance diet is essential for the healthy growth of a baby's teeth & 99.2 & 96.2 & 0.102 & \\
\hline Q11 & Night time bottle/breast feeding can cause tooth decay & 48.1 & 73.3 & 0.0001 & \\
\hline Q12 & $\begin{array}{l}\text { It is important for a child to visit the dentist before the 1st birthday or } \\
\text { after the eruption of the 1st baby tooth }\end{array}$ & 52.7 & 55.7 & 0.572 & \\
\hline Q13 & $\begin{array}{l}\text { Cleaning a baby's mouth after each feeding should begin even before } \\
\text { teeth erupt }\end{array}$ & 80.9 & 97.7 & 0.0001 & \\
\hline Q14 & $\begin{array}{l}\text { Counseling on feeding and weaning to prevent caries in infants during } \\
\text { antenatal period is required }\end{array}$ & 97.7 & 100 & 0.083 & \\
\hline
\end{tabular}

$n=131$

Table 4: Percent of correct answers for practice questions in pre- and posttest

\begin{tabular}{|c|c|c|c|c|c|}
\hline S. no. & Questions & Pretest & Posttest & pvalue & P diff \\
\hline 1 & Do you educate mothers on good oral hygiene? & 90.8 & 100 & 0.0001 & $0.7 \pm 1.1(-3$ to 6$)$ \\
\hline 2 & Do you give sweets to the children often? & 49.6 & 79.4 & 0.0001 & \\
\hline 3 & Do you teach the children about good oral hygiene? & 99.2 & 99.2 & 0.999 & \\
\hline 4 & Do you take the effort to improve your dental health knowledge? & 89.3 & 96.9 & 0.008 & \\
\hline 5 & Do you examine the oral cavity of the children? & 95.4 & 99.2 & 0.059 & \\
\hline 6 & Do you share utensils like spoons to feed children? & 74.8 & 94.7 & 0.0001 & \\
\hline
\end{tabular}
$n=131$

The pretest and posttest scores of knowledge and practice are given in Table 2. The comparison of percent of correct answers for each question on knowledge between pretest and posttests are given in Table 3 and that of practice in Table 4. The knowledge and practice were varied among AWWs from different educational background, working experience, and age but any significant association was not observed with the gain in knowledge or practice scores. The gain in knowledge according to baseline characteristics is presented in Table 5 and similarly, Table 6 presents the gain in practice by baseline variables.

\section{Discussion}

In this study, we found that the knowledge and practice of the AWWs in oral health had significantly improved with the oral health educational training. In the knowledge aspect of AWWs, there was an increase in the mean percentage of participants giving correct answers after the training from $68.23 \%$ to $77.58 \%$. The mean percentage of AWWs giving wrong answers had reduced from $24.04 \%$ to $17.82 \%$ and also those opting for "don't know" response had reduced from $77.42 \%$ to $45.8 \%$, in the pretest and posttest, respectively (Fig. 1). The practice of the AWWs also showed significant improvement in mean percentage with an increase of $11.7 \%$ after the training. The mean percentage of wrong answers had decreased from $16.79 \%$ to $5.08 \%$ in the posttest (Fig. 2). This was concordant with a study done by Kakodkar et al. ${ }^{18}$

Empowered women (skilled to make decisions and have control over the process of health and disease) are recognizably key agents in the change process who can play an effective role for health promotion. ${ }^{19}$ From the above and other similar studies, it has been found that AWWs can function as oral health guides who can create awareness and help in prevention of oral diseases. ${ }^{18,20-23}$ 
Table 5: Association of gain in knowledge score according to baseline characteristics

\begin{tabular}{|c|c|c|c|c|}
\hline Variables & Mean $\pm S D$ & Median & Mean rank & $p$ value \\
\hline \multicolumn{5}{|l|}{ Age in years } \\
\hline$<40$ & $0.9 \pm 3.0$ & 0.5 & 59.1 & \multirow[t]{3}{*}{0.182} \\
\hline $40-54$ & $1.6 \pm 2.3$ & 2.0 & 70.4 & \\
\hline$\geq 55$ & $0.7 \pm 2.9$ & 0.5 & 56.6 & \\
\hline \multicolumn{5}{|l|}{ Education } \\
\hline Matriculate & $1.4 \pm 2.4$ & 1.00 & 67.47 & \multirow[t]{3}{*}{0.096} \\
\hline High school & $1.4 \pm 2.8$ & 2.00 & 68.49 & \\
\hline Degree & $1.0 \pm 1.9$ & 1.00 & 27.42 & \\
\hline \multicolumn{5}{|c|}{ Experience in years } \\
\hline$<5$ & $1.2 \pm 2.7$ & 1.0 & 62.6 & \multirow[t]{4}{*}{0.245} \\
\hline $6-15$ & $1.5 \pm 2.4$ & 1.0 & 69.3 & \\
\hline $16-25$ & $0.5 \pm 2.7$ & 0.0 & 51.5 & \\
\hline$>25$ & $1.6 \pm 2.0$ & 2.0 & 71.2 & \\
\hline \multicolumn{5}{|l|}{ Place } \\
\hline Kadapra & $0.4 \pm 2.3$ & 0.0 & 50.6 & \multirow[t]{6}{*}{0.008} \\
\hline Kuttoor & $2.2 \pm 2.3$ & 3.0 & 82.9 & \\
\hline Nedumpuram & $2.4 \pm 2.0$ & 3.0 & 84.0 & \\
\hline Niranam & $0.6 \pm 1.9$ & 1.0 & 55.8 & \\
\hline Peringara & $2.4 \pm 2.9$ & 2.0 & 81.2 & \\
\hline $\begin{array}{l}\text { Tiruvalla } \\
\text { Muncipality }\end{array}$ & $0.8 \pm 2.6$ & 1.0 & 58.9 & \\
\hline
\end{tabular}

Table 6: Association of gain in practice score according to baseline characteristics

\begin{tabular}{lclll}
\hline Variables & Mean \pm SD & Median & Mean rank & p value \\
\hline Age in years & & & & \\
$\quad<40$ & $1.0 \pm 1.7$ & 1.0 & 73.7 & 0.201 \\
$40-54$ & $0.6 \pm 0.8$ & 0.0 & 61.9 & \\
$\quad \geq 55$ & $0.9 \pm 1.1$ & 1.0 & 73.5 & \\
Education & & & & \\
$\quad$ Matriculate & $0.7 \pm 0.9$ & 1.0 & 68.0 & 0.729 \\
High school & $0.7 \pm 1.3$ & 0.0 & 62.8 & \\
Degree & $0.6 \pm 1.1$ & 1.0 & 65.5 & \\
Experience in years & & & \\
$\quad<5$ & $0.6 \pm 0.9$ & 0.0 & 62.8 & 0.876 \\
6-15 & $0.7 \pm 1.3$ & 1.0 & 66.5 & \\
16-25 & $0.6 \pm 0.8$ & 0.0 & 62.6 & \\
$>25$ & $0.8 \pm 1.0$ & 1.0 & 68.9 & \\
Place & & & & \\
Kadapra & $0.4 \pm 2.3$ & 0.0 & 66.8 & 0.347 \\
Kuttoor & $2.2 \pm 2.3$ & 3.0 & 58.4 & \\
Nedum- & $2.4 \pm 2.0$ & 3.0 & 82.9 & \\
puram & & & & \\
Niranam & $0.6 \pm 1.9$ & 1.0 & 64.2 & \\
Peringara & $2.4 \pm 2.9$ & 2.0 & 75.5 & \\
Tiruvalla & $0.8 \pm 2.6$ & 1.0 & 60.9 & \\
Muncipality & & & & \\
\hline$n=131$ & & & &
\end{tabular}

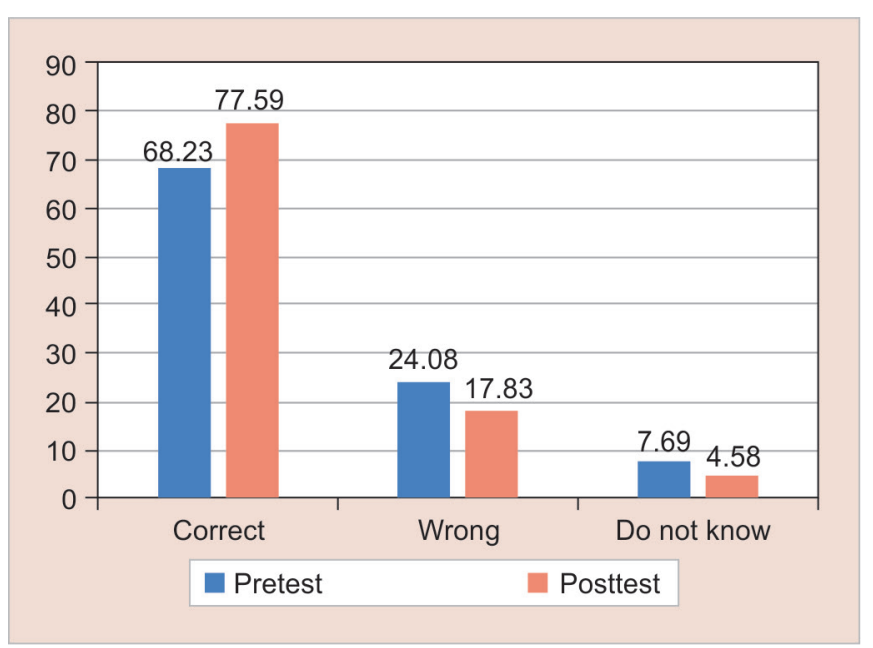

Fig. 1: Comparison of mean percentage of knowledge between pretest and posttest according to responses

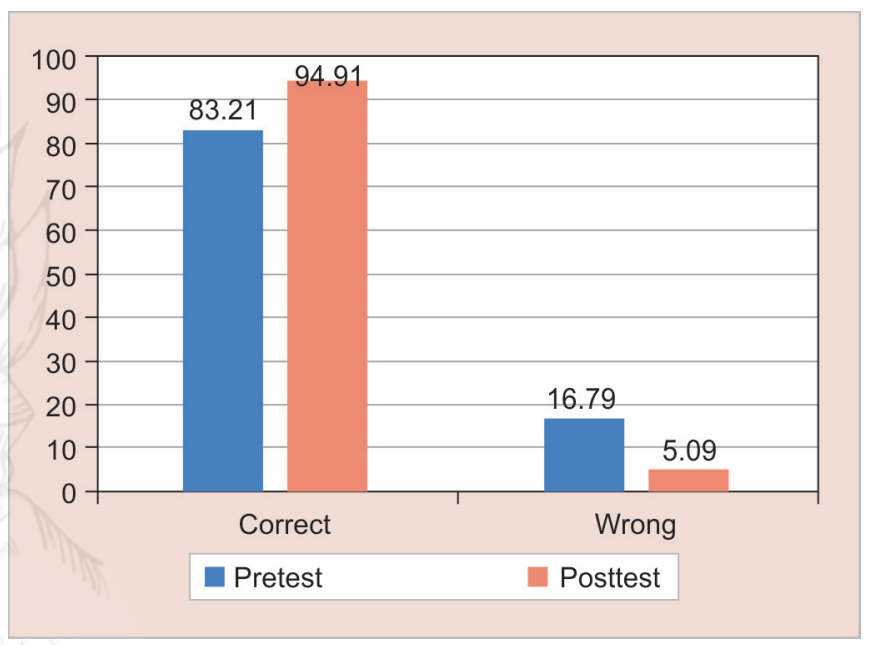

Fig. 2: Comparison of mean percentage of practice between pretest and posttest according to responses

Providing AWWs with regular oral health training will need extra effort. The ground reality about Anganwadi worker cannot be neglected in that they are overloaded with excessive record maintenance of house visits, and most of the Anganwadi workers are married and housewives. ${ }^{24,25}$ As such, training them to become oral health guides will be a challenging task. Providing them with an incentive to create interest in undergoing training session can be a motivation.

The study has its limitations that it was done over a short period of 3 months, hence long-term retention of knowledge cannot be assessed. Though the practice of the AWWs was assessed, the oral health status of the children in these centers has not determined.

AWWs can successfully perform the following functions with the oral health education provided:

- Provide information about oral hygiene aids and brushing technique for children up to 6 years of age.

- Identify the dental caries and other oral diseases of the children up to 6 years of age and referral to dentist for further treatment. 
- Educate the parents about diet, reasons for different dental problems in children, oral habits, teething, dental caries process, and the necessity for anticipatory guidance.

- Educate the pregnant women about the oral changes during pregnancy.

Educating the AWW on oral health will produce a ripple effect where the knowledge gets propagated to the mother and to her family and then to the entire community. The authorities can implement oral health training in their curriculum during the 4 month official training of the freshly recruited AWW. Anganwadi centers can be adopted by dental colleges in their vicinity.

\section{ACKnOWLedgments}

The authors would like to thank Mrs Nisha Kurien, Asst. Professor, Biostatistics, Pushpagiri College of Medical Sciences, Ramadevi, CDPO, Pulikeezh Block Panchayat, Anganwadi workers who participated in the study for their contributions to this research.

\section{References}

1. Petersen P. The World Oral Health Report 2003: continuous improvement of oral health in the 21st century - the approach of the WHO Global Oral Health Programme. Community Dent Oral Epidemiol 2003;31(Supp 1):3-24. DOI: 10.1046/j.2003.com122.x.

2. Parker $E$, Misan $G$, et al. An oral health literacy intervention for Indigenous adults in a rural setting in Australia. BMC Public Health 2012;12:461. DOI: 10.1186/1471-2458-12-461.

3. The Anganwadi Workers of India - Connecting for Health, Education, Childcare at the Grassroots Level [Internet]. Healthopine.com. 2017 [cited 17 November 2017]. Available from: http://healthopine.com/ the-Anganwadi-workers-of-india-connecting-for-health-at-thegrassroots/.

4. Social Justice, Kerala [Internet]. Swd.kerala.gov.in. 2017 [cited 17 November 2017]. Available from: http://swd.kerala.gov.in/index.php/ juvenile-justice/184.

5. Daly B, Watt RG, et al. Principles of Oral Health Promotion. Essential Dental Public Health. New Delhi: Oxford University Press; 2002. pp. 135-152.

6. Koyio L, Van der Sanden W, et al. A community-based oral health promotion model for HIV patients in Nairobi, East District in Kenya: a study protocol. J Public Health Res 2013;2(1):22-28. DOI: 10.4081/ jphr.2013.e5.

7. Khanagar $S$, Kini $P$, et al. Oral health care education and its effect on caregivers' knowledge, attitudes, and practices: A randomized controlled trial. J Int Soc Prev Community Dent 2014;4(2):122-128. DOI: 10.4103/2231-0762.139843.

8. Tewari A, Gauba K, et al. Evaluation of the change in the knowledge of community regarding infant dental care subsequent to intervention strategies through existing health manpower in rural areas of Haryana (India). J Indian Soc Pedod Prev Dent 1994;12:29-34.
9. Nakre P, Harikiran A. Effectiveness of oral health education programs: A systematic review. J Int Soc Prev Community Dent 2013;3(2):103. DOI: $10.4103 / 2231-0762.127810$.

10. Bali RK, Mathur VB, et al. National oral health survey and fluoride mapping 2002-2003 India. New Delhi: Dental Council of India; 2004.

11. WHO|Strategies for oral disease prevention and health promotion [Internet]. Who.int. 2017 [cited 17 November 2017]. Available from: http://www.who.int/oralhealth/ strategies/en/.

12. Khatib N, Zodpey S, et al. Prevalence and determinant of early childhood caries among the children attending the Anganwadis of Wardha district, India. Indian. J Dent Res 2013;24(2):199-205.

13. Basavaraj SP, Basha $S$, et al. Knowledge of early childhood caries among Anganwadi workers in Davangere city, India. Int J Oral Health Sci 2013;3:75-78. DOI: 10.4103/2231-6027.135976.

14. Shakya A, Rao A, et al. Oral health related knowledge and attitude of Anganwadi workers of Mangaluru city, India. J Chitwan Med Coll 2013;3:6-8. DOI: 10.3126/jcmc.v3i4.9545.

15. Gangwar C, Kumar M, et al. KAP toward oral health, oral hygiene and dental caries status among Anganwadi workers in Bareilly city, Uttar Pradesh: A cross-sectional survey. J Dent Sci Oral Rehabil 2014;5:53-57.

16. Shilpa M, Jain J, et al. Knowledge, attitude, and practices of Anganwadi workers regarding oral health of children in Virajpet Taluk. J Adv Oral Res 2014;5:18-23. DOI: 10.1177/22229411220140304.

17. Pulikeezhu Block Panchayat, [Internet]. Lsgkerala. in. 2017 [cited 17 November 2017]. Available from: http://Isgkerala.in/ pulikeezhublock/.

18. Kakodkar P, Matsyapal CK, et al. Anganwadi workers as Oral Health Guides: An interventional study. J Dent Res Sci Develop 2015;2:33-37. DOI: 10.4103/2348-3407.159445.

19. Kar SB, Pascual CA, et al. Empowerment of women for health promotion: a meta-analysis. Soc Sci Med 1999;49(11):1431-1460. DOl: 10.1016/S0277-9536(99)00200-2.

20. Goel S, Goel N, et al. Evaluation of short term impact of two training packages on oral health knowledge and skills of Anganwadi workers of a Northern City of India:Before and after comparison study. SRM J Res Dent Sci 2014 Oct;5(4):237. DOI: 10.4103/0976-433X. 145124.

21. Raj S, Goel S, et al. Shortterm impact of oral hygiene training package to Anganwadi workers on improving oral hygiene of preschool children in North Indian City. BMC Oral Health 2013;13(1):67. DOI: 10.1186/1472-6831-13-67.

22. Nair MKC, Renjit M, et al. Effectiveness of a community oral health awareness program. Indian Pediatr 2009;46(Suppl):s86-s90.

23. Sandhya MP, Shanthi M, et al. Effectiveness of oral health education among primary health care workers at the primary health center in Nellore district, Andhra Pradesh. J Indian Assoc Public Health Dent 2014;12(2):74-79.

24. Madhavi LH, Singh HKG. A study on knowledge of Anganwadiworkers $\&$ their problems in rural field practice area of Hebbal, Gulbarga district. J Med Educ Res 2011;1(2):62-67.

25. Seema TN. Performance of Anganwadi workers in Kerala: An evaluation and experiment to develop a model center with community participation. 